\title{
PENGARUH PENYEIMBANGAN BEBAN TRAFO DISTRIBUSI TERHADAP ARUS NETRAL
}

\author{
Oleh : \\ Surfa Yondri *), Tri Artono *), Hengki Purnama Sari**) \\ *)Staf Pengajar Jurusan Teknik Elektro Politeknik Negeri Padang \\ **)Mahasiswa Jurusan Teknik Elektro Politeknik Negeri Padang \\ Email : surfayondri@yahoo.com
}

\begin{abstract}
Load balancing is load balancing activities in each phase distribution transformers are not balanced, the goal to reduce the magnitude of the neutral current transformer because inequality between phases. This activity was done by measuring each phase transformer load, calculate the average current in each phase, and shifted the burden of heavily loaded phase to phase which has a lot fewer burdens. Load balancing is done on a regular basis every 6 months. PT. PLN (Persero) Rayon Bukittinggi perform load balancing on the distribution transformer substation 100 KVA Distribution Tabek Gadang Tower 2 times on Wednesday, 15th May 2013 at 19:30 pm and Thursday, 16 May 2013 at 19:30 pm. First, by moving the load phase $T$ to phase $S$ at 18 A. Second, by moving the burden from phase to phase $R T$ at $9 \mathrm{~A}$. and load phase $T$ to $S$ phase by $11 \mathrm{~A}$. load balancing distribution transformers 100 KVA Substation Tabek Gadang Tower is near parity with the transformer neutral currents in $14.18 \mathrm{~A}$.
\end{abstract}

Keywords : Load balancing, Neutral currents at trafo, Load each phases, Distribution tower trafo of Tabek Gadang.

\section{PENDAHULUAN}

Penyaluran energi listrik yang jauh dari pusat-pusat suplai energi listrik menuju ke pusat-pusat beban atau ke konsumen, akan menyebabkan terjadinya rugi-rugi daya (Losses) sepanjang jaringan distribusi, sehingga mengurangi kehandalan mutu pendistribusian energi listrik pada bagian hilir jaringan sistem distribusi. Salah satu penyebabnya yaitu karena tidak seimbangnya beban pada trafo distribusi tersebut. Salah satu cara untuk memperbaiki rugi-rugi daya adalah dengan menyeimbangkan beban trafo distribusi pada jaringan distribusi tersebut. Beban yang seimbang akan secara otomatis mempunyai arus netral yang kecil. Untuk membuktikan teori tersebut, maka perlu dilakukan penelitian apakah pengaruh penyeimbangan beban terhadap arus netral.

\section{TUJUAN PENELITIAN}

1. Untuk mengetahui bagaimana pengaruh dan proses penyeimbangan beban trafo.

2. Mengurangi arus netral trafo sehingga rugi-rugi daya yang ditimbulkan dapat diperbaiki.

3. Memperpanjang umur trafo dengan meminimalkan arus netralnya. 


\section{PERUMUSAN MASALAH}

Terjadinya arus netral yang besar dan losses pada jaringan sistem distribusi merupakan suatu permasalahan yang tidak dapat dihindari dalam pendistribusian energi listrik, dimana permasalahan tersebut disebabkan karena perbedaan yang mencolok dari pembagian beban dari fasa $\mathrm{R}$, fasa $\mathrm{S}$ dan fasa $T$ pada trafo distribusi.

Besarnya arus netral pada gardu distribusi tersebut akan menyebabkan terjadinya kerugian bagi pihak produsen energi listrik (PT. PLN (Persero)). Atas dasar tersebut permasalahan yang penulis bahas yaitu mengenai pengaruh penyeimbangan beban trafo distribusi terhadap arus netral trafo distribusi.

\section{TINJAUAN PUSTAKA}

\section{Keseimbangan Beban}

Kebutuhan pasokan energi listrik sudah menjadi kebutuhan utama bagi masyarakat saat ini. Dengan demikian dibutuhkan cara penyaluran energi listrik yang paling efektif. Namun memang tidak akan ada hal yang ideal di dunia ini. Begitu pula dengan penyaluran energi listrik. Sistem penyaluran energi listrik yang dilakukan di Indonesia adalah sistem penyaluran dengan 3 fasa (fasa $R$, fasa $\mathrm{S}$, dan fasa $\mathrm{T}$ ).

Selain itu Indonesia juga memakai sistem transmisi dan distribusi dimana sistem transmisi adalah sistem penyaluran daya dengan menaikkan tegangan yang selanjutnya diturunkan lagi pada sistem distribusi. Dalam proses menaikkan dan menurunkan tegangan digunakanlah transformator 3 fasa.

Dalam keadaan ideal, transformator 3 fasa akan mempunyai nilai yang sama pada tiap fasanya, yang berbeda hanyalah sudut fasanya yaitu harus $120^{\circ}$.
Namun pada penerapannya, keadaan ideal tersebut sangat sulit terjadi dikarenakan tiap fasa pada sisi sekunder akan menyalurkan daya tiap fasa dengan beban yang berbeda tiap fasanya. Hal ini akan menyebabkan beban tidak seimbang pada masing-masing fasanya. efek dari ketidakseimbangan fasa tersebut adalah akan timbul arus netral. Arus ini akan menyebabkan losses, yaitu losses akibat adanya arus netral pada penghantar netral trafo dan losses akibat arus netral yang mengalir ke tanah.

\section{Syarat Keadaan Seimbang}

1. Ketiga vektor arus/tegangan sama besar.

2. Ketiga vektor saling membentuk sudut $120^{\circ}$ satu sama lain.

\section{Keadaan Tidak Seimbang}

1. Ketiga vektor sama besar tetapi tidak membentuk sudut $120^{\circ}$ satu sama lain.

2. Ketiga vektor tidak sama besar tetapi membentuk sudut $120^{\circ}$ satu sama lain.

3. Ketiga vektor tidak sama besar dan tidak membentuk sudut $120^{\circ}$ satu sama lain.

Sebagai akibat dari ketidakseimbangan beban antara tiaptiap fasa pada sisi sekunder trafo (fasa R, fasa $S$, fasa $T$ ) mengalir arus di netral trafo. Arus yang mengalir pada penghantar netral trafo ini menyebabkan losses (rugi-rugi).

\section{Phasor Beban Seimbang dan Tidak Seimbang}

Gambar 1 memperlihatkan bentuk diagram fasor dari tegangan dan arus dari sistem tiga fasa yang dihubungkan 
dengan beban seimbang. Hal ini dapat kita perhatikan dari bentuk diagram fasor masing-masing fasa yang dipisahkan oleh sudut rugi-rugi atau $\cos \Phi$ dari penggunaan beban masing-masing jalur fasa.

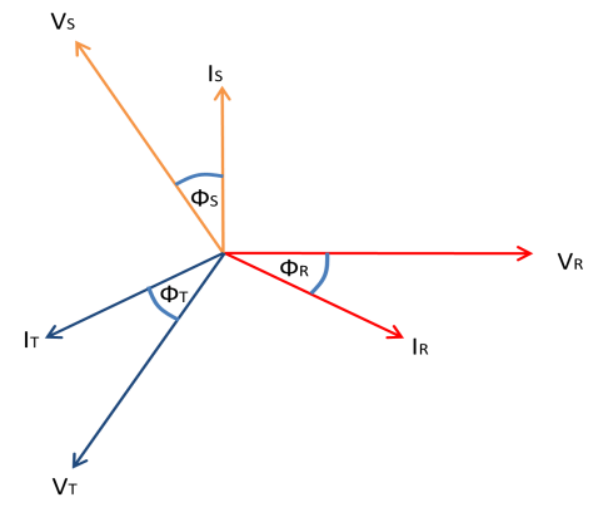

Gambar 1. Fasor dari tegangan dan arus dari sistem tiga fasa keadaan seimbang [http://bersinar2010.files.wordpress.com/ Gambar 2]

Jika terjadi beban tidak seimbang pada jaringan distribusi tegangan rendah maka pada penghantar netral akan mengalir arus listrik. Hal ini akan mempertahankan magnitudo tegangan ke titik netral yang melintasi setiap pasa ke beban. Arus-arus saluran tidak sama dan arus pada diagram fasor tidak memiliki simetri.

Gambar 2 merupakan gambar diagram fasor dari tegangan dan arus dari sistem tiga fasa yang dihubungkan dengan beban yang tidak seimbang.

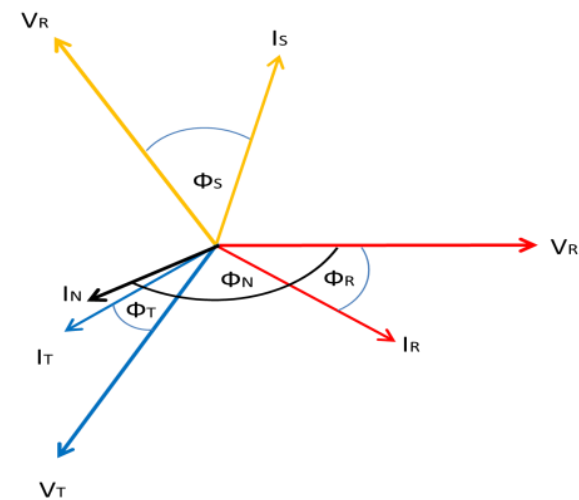

Gambar 2. Fasor dari tegangan dan arus dari sistem tiga fasa keadaan tidak seimbang

[http://bersinar2010.files.wordpress.com/ Gambar 2]

Karena pada beban tidak seimbang akan muncul arus netral maka persamaan untuk vektor diatas adalah : $\mathrm{I}_{\mathrm{N}}=\mathrm{I}_{\mathrm{R}}+\mathrm{I}_{\mathrm{S}}+\mathrm{I}_{\mathrm{T}} \neq 0$

Dimana arus netral dapat diperhitungkan dengan rumus berikut :

$$
I_{N}=\sqrt{\left(I_{R}{ }^{2}\right)+\left(I_{S}{ }^{2}\right)+\left(I_{T}{ }^{2}\right)-\left(I_{R} \times I_{S}\right)-\left(I_{R}-I_{T}\right)\left(I_{S} \times I_{T}\right)}
$$

\section{Penyebab Beban Pincang}

Penyebab dari ketidakseimbangan beban ini diantaranya adalah sebagai berikut :

1. Pasang baru pada bagian kabel yang mudah untuk penyambungan. Banyaknya pemasangan pelanggan baru oleh biro pada bagian kabel yang mudah untuk dipasangi pierching connector tanpa memperhatikan phasa yang terpasang pada saat itu. Hal ini terjadi sebagian besar pada jaringan SKUTR yang memakai kabel LVTC. Hal ini diakibatkan karena saat pemasangan pierching connector pada LVTC tersebut, pemasangan harus melonggarkan kabel tersebut dari pilinannya.

2. Banyaknya pelanggan pada suatu sambungan deret. Tidak semua pelanggan listrik memiliki rumah tinggal dekat jaringan, untuk mengatasinya maka dibuat suatu SR deret. Peraturannya suatu SR deret dibatasi maksimal 5 pelanggan tiap fasanya, namun pada pelaksanaannya banyak SR deret yang memiliki pelanggan lebih dari 5 pelanggan dalam satu fasa. Hal ini diakibatkan adanya penambahan pelanggan yang tidak selalu terjadi pada pelanggan yang dekat jaringan JTR saja, 
melainkan ada juga yang agak jauh dari jaringan, sehingga oleh pemasang diambilkan dari jaringan SR yang terdekat. Pemasangan tersebut tidak memperhatikan SR deret yang telah tersambung pada satu fasa tersebut. Sehingga menyebabkan beban pincang pada trafo karena fasa tersebut terlalu banyak menanggung beban. Selain mengakibatkan beban pincang banyaknya pelanggan pada suatu SR deret akan mengakibatkan tegangan ujung pada SR dert tersebut drop (jauh dari tegangan normal).

3. Kurangnya pengawasan di lapangan. Dalam pelaksanaan pemasangan sambungan baru, pada umumnya pengawas lapangan langsung percaya kepada pelaksana bahwa apa yang dikerjakan sesuai dengan perintahnya. Untuk itu perlu dicek ulang dengan cara melakukan pengukuran kembali, kemudian membandingkannya dengan hasil pengukuran sebelum pelaksanaan pemasangan. Dari data tersebut dapat diketahui adanya penambahan beban pada phasa terdapat sambungan baru.

\section{HASIL DAN PEMBAHASAN}

Pemeliharaan adalah suatu kegiatan yang meliputi pekerjaan pemeriksaan, pencegahan, perbaikan dan penggantian peralatan pada sistem jaringan distribusi secara terjadwal atau tidak. Salah satu contoh dari pemeliharaan distribusi adalah penyeimbangan beban.

Penyeimbangan beban adalah suatu kegiatan yang terdiri dari pengukuran awal, hingga pemerataan beban tiap fasa yang tidak seimbang (pincang) yang bertujuan agar arus pada netral tersebut berkurang, sehingga mengurangi kerugian terhadap perusahaan listrik (PLN) tersebut. Pelaksanaan penyeimbangan beban yang dilakukan yaitu pada tiang tegangan rendah (TR) atau pada sambungan rumah (SR).

Penyeimbangan beban ini juga memberikan pengaruh yang besar terhadap umur trafo. Karena jika pada salah satu fasa bebannya sudah melebihi batas yang diperbolehkan, maka akan dapat menyebabkan obstick kabel pada gardu tersebut terbakar. Beban yang sudah melebihi batas tersebut dapat ditandai dengan fuse atau sekering pada gardu akan panas dan mengeluarkan asap jika terlalu berlebihan. Jika hal tersebut terjadi dan tidak segera dilakukan penyeimbangan beban maka dapat menyebabkan fasa tersebut akan bersinggungan dengan fasa lainnya yang akan membuat trafo tersebut meledak. Solusinya yaitu dengan cara memindahkan sebagian beban pada rute yang berat ke rute lainnya yang bebannya masih ringan.

Penyeimbangan beban yang dilakukan PT. PLN (persero) ini yaitu berdasarkan waktu yang telah ditentukan pelaksanannya yaitu $1 \mathrm{x}$ persemester. Tiap gardu distribusi dilaksanakan pengukuran beban setiap 6 bulan sekali. Dan dari hasil pengukuran, maka dilaksanakan penyeimbangan beban jika dibutuhkan.

Dari sebuah pengukuran beban trafo di Rayon Bukittinggi tepatnya pada Gardu Distribusi Tabek Gadang 100 KVA didapatkan hasil pengukuran beban tak seimbang. Dari pengukuran tersebut terlihat beban pincang sehingga dimasukkan dalam kegiatan penyeimbang beban trafo. Pengukuran pertama dilakukan pada beban puncak yaitu pada hari Selasa 14 Mei 2013 pukul 19.30. Data-data beban trafo tersebut sebagai berikut :

Tabel 1. Pengukuran beban sebelum diseimbangkan

\begin{tabular}{|c|c|c|c|}
\hline $\begin{array}{c}\text { Fasa / } \\
\text { beban }\end{array}$ & $\begin{array}{c}\text { Beban } \\
\text { Induk }\end{array}$ & $\begin{array}{c}\text { Rute } \\
1\end{array}$ & $\begin{array}{c}\text { Rute } \\
2\end{array}$ \\
\hline
\end{tabular}




\begin{tabular}{|c|c|c|c|}
\hline $\mathrm{R}$ & 88 & 62 & 27 \\
\hline $\mathrm{S}$ & 69 & 61 & 8 \\
\hline $\mathrm{T}$ & 104 & 82 & 23 \\
\hline
\end{tabular}

Dari hasil pengukuran beban trafo diatas dapat terlihat bahwa beban pada phasa $\mathrm{T}$ jauh lebih besar dari pada phasa lainnya, sedangkan fasa $\mathrm{S}$ lebih kecil dibandingkan fasa lainnya sehingga arus pada netral bisa dikatakan besar sekali, yang disebabkan ketidakseimbangannya beban ini. Arus netral tersebut adalah sebagai berikut :

$$
\begin{aligned}
& I_{N}=\sqrt{\left(I_{R}{ }^{2}\right)+\left(I_{S}{ }^{2}\right)+\left(I_{T}{ }^{2}\right)-\left(I_{R} \times I_{S}\right)-\left(I_{R}-I_{T}\right)\left(I_{S} \times I_{T}\right)} \\
& =\sqrt{\left(88^{2}\right)+\left(69^{2}\right)+\left(104^{2}\right)-(88 \times 69)-(88 \times 104)-(69 \times 104)} \\
& =\sqrt{7744+4761+10816-6072-9152-7176} \\
& =\sqrt{23321-22400} \\
& =\sqrt{921}
\end{aligned}
$$$$
I_{N}=30,35 \mathrm{~A}
$$

Untuk mengatasi permasalahan ini maka harus segera dilaksanakan kegiatan penyeimbang beban trafo. Dari data pengukuran awal, direncanakan untuk memindahkan fasa $\mathrm{T}$ ke fasa $\mathrm{S}$ sebanyak 17 A. Nilai tersebut diperoleh dari perhitungan sebagai berikut :

Nilai rata - rata per fasa $=\underline{\text { Beban } \mathrm{R}+\text { Beban } \mathrm{S}+\text { Beban } \mathrm{T}}$

$$
=\frac{88+69+104}{3}=\frac{261}{3}=87 \mathrm{~A}
$$

Karena fasa $\mathrm{R}$ sudah mendekati nilai $87 \mathrm{~A}$, sedangkan fasa $\mathrm{S}$ kurang dari rata-rata, maka dari itu fasa $\mathrm{T}$ yang sudah jauh melebihi nilai rata-rata beban harus dipindahkan agar ketiga fasa tersebut mendekati nilai seimbang. Agar mencapai nilai yang seimbang, maka beban dari fasa $\mathrm{T}$ harus dipindahkan sebanyak 17 A ke fasa S. Dilihat dari kedua rute, maka rute yang beban nya dipindahkan yaitu fasa $T$ rute 1 sebanyak $17 \mathrm{~A}$

Dengan memperkirakan beban yang digunakan sekitar $70 \%$ dari daya pelanggan, maka akan dipindahkan sebanyak 6 pelanggan dari fasa T rute 1 ke fasa $S$. Yang dipindahkan yaitu fasa $T$ tepatnya pada tiang yang terletak 2 gawang dari gardu distribusi tersebut.
Data pelanggan tersebut adalah sebagai berikut :

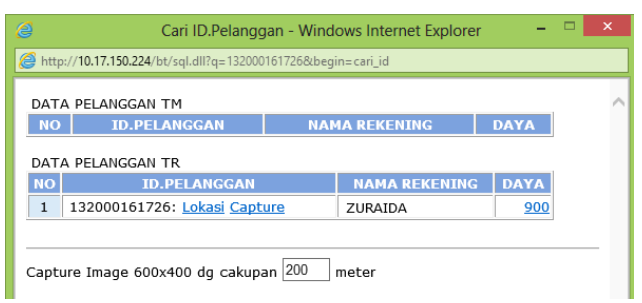

Gambar 3. Data pelanggan pertama yang dipindah ke fasa $\mathrm{S}(4 \mathrm{~A})$

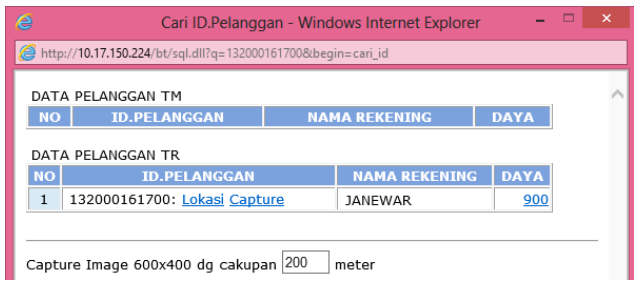

Gambar 4. Data pelanggan kedua yang dipindah ke fasa $\mathrm{S}(4 \mathrm{~A})$

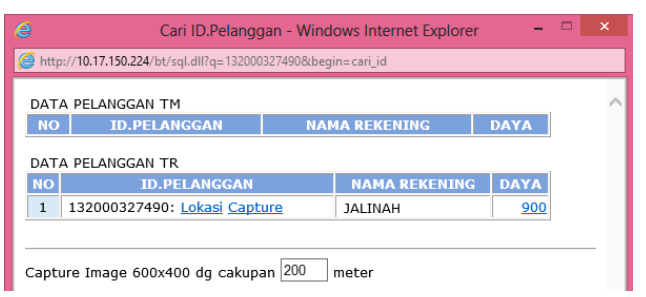

Gambar 5. Data pelanggan ketiga yang dipindah ke fasa $\mathrm{S}(4 \mathrm{~A})$

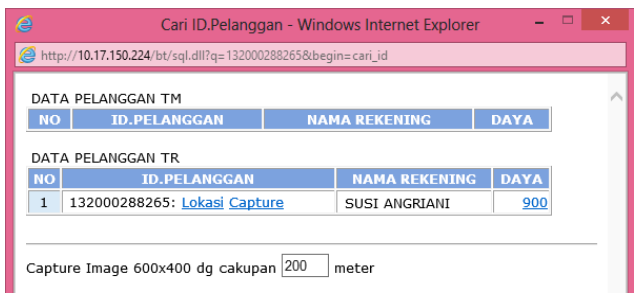

Gambar 6. Data pelanggan keempat yang dipindah ke fasa $\mathrm{S}(4 \mathrm{~A})$ 


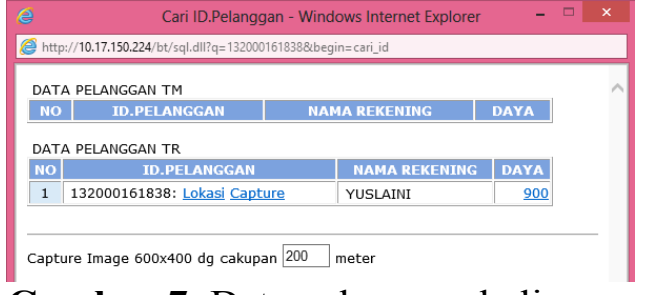

Gambar 7. Data pelanggan kelima yang dipindah ke fasa S (4A)

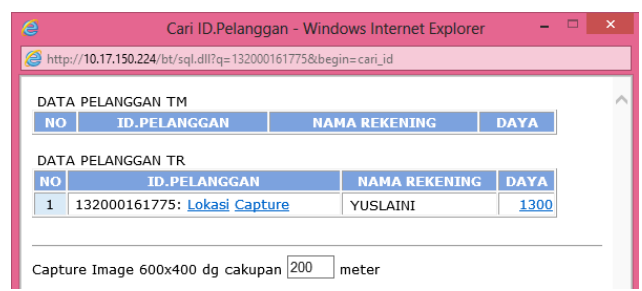

Gambar 7. Data pelanggan keenam yang dipindah ke fasa $S(6 \mathrm{~A})$

Dari data pelanggan tersebut dapat diketahui jumlah daya seluruhnya yaitu sebesar 26 A. Sedangkan jika dirata-rata kan pemakaian sebesar 70\% maka seluruhnya berjumlah $18 \mathrm{~A}$. Maka seluruh pelanggan fasa $\mathrm{T}$ pada tiang tersebut, dapat dipindahkan ke fasa $\mathrm{S}$.

puncak setelah dilakukan penyeimbangan beban pada hari rabu 15 mei 2013 pada pukul 19.30 adalah sebagai berikut:

Tabel 2. Pengukuran beban setelah dilakukan penyeimbangan beban yang pertama

\begin{tabular}{|l|l|l|l|}
\hline $\begin{array}{l}\text { Fasa / } \\
\text { beban }\end{array}$ & $\begin{array}{l}\text { Beban } \\
\text { Induk }\end{array}$ & Rute 1 & Rute 2 \\
\hline $\mathrm{R}$ & 81 & 60 & 23 \\
\hline $\mathrm{S}$ & 79 & 69 & 8 \\
\hline $\mathrm{T}$ & 110 & 83 & 24 \\
\hline
\end{tabular}

Dari data tersebut ternyata masih harus dilaksanakan penyeimbangan beban lagi karena ada peningkatan beban pada salah satu fasa pada saat pengukuran beban puncak. Hal ini disebabkan adanya peningkatan pemakaian listrik oleh konsumen dibandingkan dengan malam sebelumnya. Maka dilaksanakan penyeimbangan beban ke 2 pada hari kamis 16 mei 2013. Nilai arus netral sebelum dilaksanakannya penyeimbangan beban adalah sebagai berikut :

$$
\begin{aligned}
& I_{N}=\sqrt{\left(I_{R}{ }^{2}\right)+\left(I_{S}{ }^{2}\right)+\left(I_{T}{ }^{2}\right)-\left(I_{R} \times I_{S}\right)-\left(I_{R}-I_{T}\right)\left(I_{S} \times I_{T}\right)} \\
& =\sqrt{\left(81^{2}\right)+\left(79^{2}\right)+\left(110^{2}\right)-(81 \times 79)-(81 \times 110)-(79 \times 110)} \\
& =\sqrt{6561+6241+12100-6399-8910-8690} \\
& =\sqrt{24902-23999} \\
& =\sqrt{903}
\end{aligned}
$$

Dari hasil pengukuran beban tersebut dapat dihitung nilai rata-rata masing-masing fasa dalam keadaan seimbang adalah sebagai berikut :

Nilai rata - rata per fasa $=$ Beban $\mathrm{R}+$ Beban $\mathrm{S}+$ Beban $\mathrm{T}$

$$
=\frac{81+79+110}{3}=\frac{270}{3}=90 \mathrm{~A}
$$

Dari hasil pengukuran beban trafo diatas dapat terlihat bahwa beban pada phasa $T$ masih jauh lebih besar dari pada phasa lainnya. Dari nilai rata-rata tersebut, maka yang harus dilakukan yaitu memindahkan beban pada fasa $T$ sebanyak 9 A ke fasa $\mathrm{R}$, dan sebanyak 11 A ke fasa $\mathrm{S}$ agar nilai tersebut mencapai niliai yang mendekati keseimbangan.

Berdasarkan data tersebut, maka harus dilakukan survei terlebih dahulu pelanggan mana yang akan dipindahkan. Dari survey tersebut diperoleh data pelanggan yang akan dipindahkan yaitu sebagai berikut :

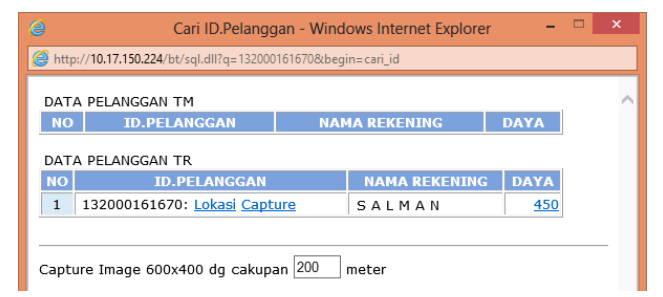

Gambar 8. Data pelanggan pertama yang dipindah ke fasa $\mathrm{S}(2 \mathrm{~A})$ 


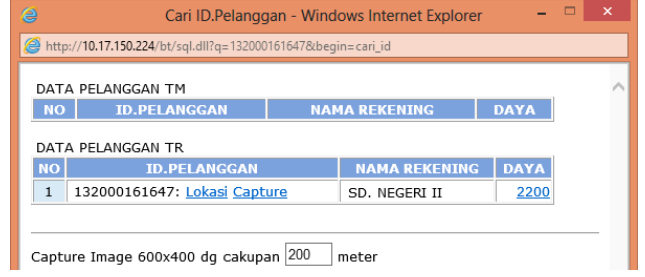

Gambar 9. Data pelanggan kedua yang dipindah ke fasa $S(10 \mathrm{~A})$

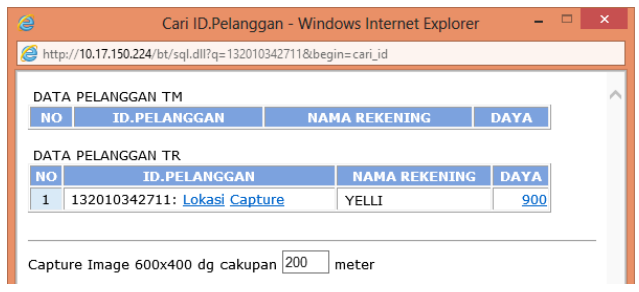

Gambar 10. Data pelanggan ketiga yang dipindah ke fasa S (4A)

Pelanggan yang dipindah ke fasa $S$ yaitu sebanyak 3 pelanggan dengan total beban yang dipindahkan yaitu sebanyak 16 A. Beban yang dipindahkan tersebut adalah diperkirakan beban yang digunakan berjumlah $70 \%$ dari batas beban. Sehingga nilainya mendekati nilai yang harus dipindahkan. Sedangkan pelanggan yang dipindahkan ke fasa $R$ yaitu sebagai berikut :

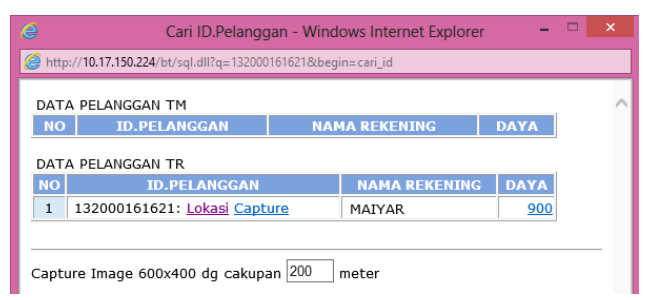

Gambar 11. Data pelanggan pertama yang dipindah ke fasa $R$ (4A)

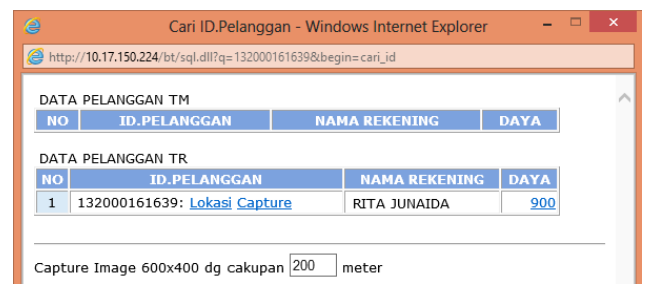

Gambar 12. Data pelanggan kedua yang dipindah ke fasa $\mathrm{R}(4 \mathrm{~A})$

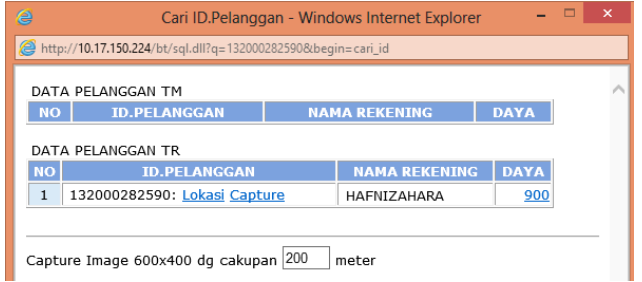

Gambar 13. Data pelanggan ketiga yang dipindah ke fasa $R$ (4A)

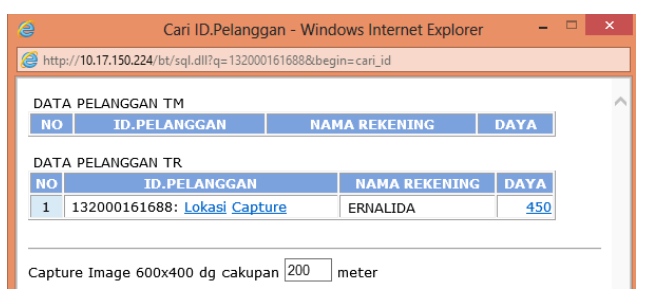

Gambar 14. Data pelanggan keempat yang dipindah ke fasa $\mathrm{R}(2 \mathrm{~A})$

Setelah selesai memindahkan beban sesuai dengan data pelanggan diatas, maka setelah itu dilakukan pengukuran beban puncak. Pada saat melakukan pengukuran beban puncak pada malamnya pukul 19.30 diperoleh data sebagai berikut :

Tabel 3. Pengukuran beban setelah dilakukan penyeimbangan beban kedua mendekati seimbang

\begin{tabular}{|l|l|l|l|}
\hline $\begin{array}{l}\text { Fasa / } \\
\text { beban }\end{array}$ & $\begin{array}{l}\text { Beban } \\
\text { Induk }\end{array}$ & Rute 1 & Rute 2 \\
\hline $\mathrm{R}$ & 88 & 61 & 26 \\
\hline $\mathrm{S}$ & 83 & 75 & 8 \\
\hline $\mathrm{T}$ & 99 & 76 & 23 \\
\hline
\end{tabular}

Setelah selama 3 hari kami melakukan kegitan penyeimbangan beban trafo pada gardu tabek gadang ini, dimulai dari pemilihan trafo yang memiliki beban yang tak seimbang, perbaikan sambungan deret, pengukuran beban puncak setelah perbaikan sambungan deret, pemindahan beban dari fasa yang memiliki beban yang berat ke fasa yang memiliki beban yang ringan per rutenya, pengukuran beban puncak lagi setelah pekerjaan 
pemindahan beban, setelah beban sudah dianggap mendekati seimbang barulah pekerjaan dilapangan dikatakan selesai. Berkat ketabahan dan keringat dilapangan kami dapatkan hasil pekerjaan yang memuaskan berupa pengukuran beban puncak yang mendekati seimbang. Dengan mendapatkan beban yang mendekati seimbang, tentunya juga diperoleh arus netral yang kecil.

Nilai arus netral setelah dilaksanakannya penyeimbangan beban adalah sebagai berikut :

$$
\begin{aligned}
& I_{N}=\sqrt{\left(I_{R}{ }^{2}\right)+\left(I_{S}{ }^{2}\right)+\left(I_{T}{ }^{2}\right)-\left(I_{R} \times I_{S}\right)-\left(I_{R}-I_{T}\right)\left(I_{S} \times I_{T}\right)} \\
& =\sqrt{\left(88^{2}\right)+\left(83^{2}\right)+\left(99^{2}\right)-(88 \times 83)-(88 \times 99)-(83 \times 99)} \\
& =\sqrt{7744+6889+9801-7304-8712-8217} \\
& =\sqrt{24434-24233} \\
& =\sqrt{201}
\end{aligned}
$$

\section{$\mathrm{I}_{\mathrm{N}} \quad=14,18 \mathrm{~A}$}

Dari pengukuran beban puncak diatas dapat kita lihat setelah beban mendekati seimbang atau bisa dibilang seimbang arus netralnya menjadi lebih kecil, yang mana sebelum beban seimbang arus netral totalnya 30,35 A dan setelah bebannya diseimbangkan arus netral totalnya menjadi $14,18 \mathrm{~A}$.

\section{KESIMPULAN}

Dari pembahasan diatas maka dapat diambil beberapa kesimpulan antara lain adalah sebagai berikut :

1. Penyeimbangan beban trafo yang dilakukan dapat memperkecil losses yang terjadi pada JTR, hal ini ditandai dengan mengecilnya arus yang mengalir pada bagian netral.

2. Semakin besar ketidakseimbangan beban pada transformator maka arus netral dan losses di saluran netral transformator semakin besar pula.

3. Besar arus netral sebelum beban diseimbangkan yaitu 30,35 A, sedangkan setelah dilakukan penyeimbangan beban maka diperoleh arus netral sebesar 14,18 A. Hal ini terbuki bahwa penyeimbangan beban dapat memperkecil arus netral trafo.

\section{DAFTAR PUSTAKA}

Edminister, Joseph A. 1994. Rangkaian Listrik. Jakarta : Schaum

Fitzgeral, A.E dkk. 1985. Dasar-Dasar Elektroteknik. Jakarta : Erlangga

http://bersinar2010.files.wordpress.com http://electricdot.wordpress.com/2012/10 /15/pengaruhketidakseimbanganpembebanan-pada-trafodistribusi

Pirade, Yulius Salu. 2009. "Studi Beban Tidak Seimbang Terhadap Arus Netral Pada

Transformator Distribusi".MEKTEK.XI (3) : 181-183

Wijaya, Muchtar. 2000. "Dasar-Dasar Mesin Listrik". Jakarta : Djambatan 